\title{
La vida en sentido extramoral. Ensayo sobre la inquietud de sí como política de la desindividualización ${ }^{1}$
}

\author{
Life in an extramoral sense. An essay on the care of \\ the self as a politics of deindividualisation
}

Silvana Paola Vignale ${ }^{2}$

INCIHUSA / CONICET, Argentina

Recepción: 17 de julio del 2021

Evaluación: 22 de septiembre del 2021

Aceptación: 23 de septiembre el 2021

\footnotetext{
1 El presente trabajo se desarrolla en el marco de la investigación que realizo en CONICET titulada "Genealogía moral de la pena. Entramados jurídicos, económicos y morales en el gobierno de la individualización”. Se inscribe también en el proyecto que dirijo en CONICET (Proyectos de Investigación Plurianual - PIP 2017): "Gubernamentalidad neoliberal y procesos de subjetivación: hacia una ontología crítica del presente".

2 Doctora en Filosofía (UNLa). Investigadora en el Instituto de Ciencias Humanas, Sociales y Ambientales (INCIHUSA), Consejo Nacional de Investigaciones Científicas y Técnicas - CONICET.

Correo electrónico: svignale@conicet-mendoza.gob.ar/silvanavignale@hotmail.com
} 


\title{
Resumen
}

El presente artículo aborda el trabajo de Michel Foucault sobre el bíos -parte de su estudio sobre la inquietud de sí en el ascetismo pagano- en el marco de luchas contra el gobierno de la individualización. Desde esta perspectiva se sostiene que una ética de sí, lejos de presentarse como salida individualista, responde a una historia marginal respecto de las relaciones entre sujeto y verdad. La historia del bíos quedó oscurecida por la historia del desarrollo del alma-sujeto, de una metafísica de la identidad y del individuo como efecto del gobierno de la individualización. A partir de ello se busca hacer converger dos genealogías. Por una parte, la de la ontología del yo y de la docilidad del cuerpo -coincidente con el desarrollo de la inquietud de sí del modelo platónico de la reminiscencia y de la exégesis del yo del ascetismo cristiano-, con una genealogía de la moral que manifiesta la hostilidad del ideal ascético hacia la vida. En este sentido, el rescate de la historia del bíos se manifiesta no solo como política de la desindividualización, sino que reinstala, a la vez, para nuestro presente, la paradoja de la imposibilidad y la urgencia de una ética de sí contemporánea.

Palabras claves: bíos, individualización, sujeto, genealogías.

\begin{abstract}
This article approaches Michel Foucault's work on the bios -as part of his study of the care of the self in pagan asceticism- in the context of struggles against the government of individualisation. From this perspective, it is argued that an ethics of the self, far from presenting itself as an individualistic way out, responds to a marginal history of the relations between subject and truth. The history of the bios was obscured by the history of the development of the subject-soul, of a metaphysics of identity and of the individual as an effect of the government of individualisation. The aim is to bring together two genealogies. On the one hand, that of the ontology of the self and of the docility of the body -coinciding with the development of the care of the self of the Platonic model of reminiscence and of the exegesis of the self of Christian asceticism- with a genealogy of morality that manifests the hostility of the ascetic ideal towards life. In this sense, the rescue of the history of the bios manifests itself not only as a politics of deindividualisation; it reinstates, at the same time, for our present, the paradox of the impossibility and the urgency of a contemporary ethics of the self.
\end{abstract}

Keywords: bios, individualization, subject, genealogies. 


\section{Bíos como bisagra entre la genealogía del poder y la crítica del sujeto}

Entre los años 1976 y 1984, Michel Foucault modifica el curso de sus investigaciones mediante un triple desplazamiento. Un desplazamiento teórico, en cuanto pasa de interrogarse por las reglas de formación de los discursos y por las técnicas de sujeción a las normas, a preguntarse por las modalidades y formas de relación consigo mismo. Un desplazamiento histórico, de la modernidad de Occidente a la antigüedad grecorromana y, por último, un desplazamiento metodológico, de un trabajo arqueo-genealógico de los sistemas a una crítica o problematización del sujeto. La noción de 'bios' puede ser interpretada como el pasaje o bisagra entre sus estudios sobre una genealogía del poder y una genealogía del sujeto moral o crítica del sujeto. Ese tránsito se sitúa en la reelaboración de su proyecto de La historia de la sexualidad. El uso de los placeres y La inquietud de sí revelan un giro en el que puede apreciarse que la cuestión del bios se presenta como un gozne: del último capítulo en La voluntad de saber, "Derecho de muerte y poder sobre la vida", donde define la biopolítica como esa forma de poder que se dirige a la regulación de la vida de la población -indispensable para el desarrollo del capitalismo, para lograr la inserción controlada de los cuerpos en los aparatos de producción (Foucault, 2009, p. 133)-, a las "artes de la existencia" y "técnicas de sí" en El uso de los placeres.

En los últimos cursos, Foucault insiste en que sus desarrollos buscan trazar una historia de las relaciones entre sujeto y verdad. Así, en Subjetividad y verdad (2020), diferencia su modo de abordar estas relaciones de otras dos tradiciones. Por un lado, de una tradición filosófica que va desde Platón hasta Kant, centrada en determinar fundamentalmente si el sujeto puede conocer la verdad y, por lo tanto, en cuáles son las condiciones objetivas del conocimiento. En segundo lugar, de una tradición positivista, que va en un sentido inverso a la anterior, y cuyos interrogantes han pasado por determinar si se puede conocer la verdad del sujeto.

Foucault busca abordar las relaciones entre sujeto y verdad a partir de una manera histórico-filosófica, que consiste en considerar la existencia en toda cultura $-\mathrm{y}$ en nuestra cultura o civilización en particular-, de discursos sobre el sujeto considerados como verdaderos y que, con independencia de su valor universal de verdad, funcionan, circulan, tienen el peso de la verdad. El problema histórico para Foucault es que “(...) habida cuenta de 
lo que son esos discursos, en su contenido y en su forma, habida cuenta de lo que son los lazos de obligación que nos ligan a esos discursos de verdad, ¿qué experiencia hacemos de nosotros mismos toda vez que esos discursos existen?" (Foucault, 2020, p. 27).

El interrogante histórico de Foucault podría traducirse de esta manera: ¿qué debemos hacer con nosotros mismos en vista de que esos discursos buscan objetivarnos y esas prácticas sujetarnos a determinadas normas? Se trata de la intervención del sujeto en su propia configuración subjetiva, aspecto que nutre también el desarrollo de lo que denomina "actitud crítica", en cuanto es necesario problematizar qué queremos aceptar y qué queremos rechazar de nosotros mismos ${ }^{3}$.

No es poco importante explicitar en esta nueva etapa que el sujeto no se concibe sobre la base de una teoría previa y universal ni tampoco como fundamento. Una vez más, en este nuevo giro en sus investigaciones, Foucault nos advierte con la precaución de método de no partir de universales antropológicos, sino de la constitución histórica de los sujetos, con lo cual se recalca el trabajo con la subjetivación concebida como un proceso y no como un resultado. Lo mismo ocurre respecto de la concepción de "verdad". En el modo de plantear el problema de las relaciones entre sujeto y verdad en esta manera históricofilosófica, la verdad no se define como un conocimiento universalmente válido, sino como un sistema de obligaciones, independientemente de la cuestión de la verdad y la falsedad.

Podemos advertir que Foucault sigue los pasos ya realizados por Friedrich Nietzsche, al asociar la verdad a un sistema de obligaciones, es decir, al desnudar su carácter moral ${ }^{4}$. Para el filósofo francés, un "régimen de verdad" es un régimen político en cuanto estos actos de verdad se dan en el marco del “(...) conjunto de procedimientos y las instituciones que, de manera más o menos apremiante, comprometen a los individuos, los obligan a obedecer decisiones (...)" (Foucault, 2014, p. 116). Ese compromiso del individuo define en última instancia la responsabilidad de sí mismo, asunto que es

\footnotetext{
3 Recientemente he desarrollado aspectos de la noción de "crítica" de Foucault en el artículo "Ethos crítico y a priori histórico de una experiencia posible. Contribución filosófica a la noción de crítica desde una ontología del presente" (2020a).

4 Puede seguirse la referencia de Foucault a Nietzsche en lo que respecta a la cuestión de la verdad en "La verdad y las formas jurídicas" (2010) o en las Lecciones de la voluntad de saber (2012).
} 
expuesto por Nietzsche en el Primer Tratado de La genealogía de la moral, mostrando la articulación entre la facultad de hacer promesas y lo que aquí llamamos gobierno de la individualización. Nos referimos a la configuración del individuo en el marco de una relación con la verdad que -como veremosse desprende de una tradición fundadora de la metafísica de la identidad y del individuo político moderno. Nietzsche sostiene que el auténtico trabajo del hombre sobre sí mismo se inscribe en la larga historia de la responsabilidad y de su obligación con la verdad en lo que respecta al desarrollo de la facultad de hacer promesas. El hombre fue hecho, de esta manera, calculable. Y situándonos al final de este proceso “(...) encontraremos como el fruto más maduro de su árbol, al individuo soberano (...)” (Nietzsche, 1998, p. 67). Esa responsabilidad, esa obligación de responder de acuerdo a lo que se ha prometido, se ha convertido para Nietzsche en su "instinto dominante", en aquello que el hombre llama su "conciencia".

Volviendo sobre la manera histórico-filosófica de abordar las relaciones entre sujeto y verdad, encontramos que la modulación de Foucault para los años que seguirán, no se centrará en determinar la experiencia del sujeto con relación a los discursos de verdad sobre la locura, la enfermedad, la muerte y el crimen -trabajo del que se había ocupado hasta ese momento-, sino de aplicar esta modulación al dominio de la aphrodisia de manera específica -en el marco de las modificaciones de su proyecto de La historia de la sexualidad-, pero en términos más generales, a la relación consigo mismo, tomando como punto de partida la noción de "inquietud de sí” (Foucault, 2001a, p. 17).

En otras palabras, pasa del estudio de una “objetivación de sí en un discurso de verdad", en la que el sujeto es apropiado por el discurso de verdad y producido como tal (es el caso del loco, del criminal, etcétera), a una "subjetivación del discurso de verdad" o dramática del discurso verdadero, en la que el sujeto se encuentra unido al enunciado y supone un vínculo entre el acceso a la verdad y la transformación de sí mismo (pp. 316-317).

5 He desarrollado lo que hace referencia a la constitución del individuo en La genealogía de la moral, en el artículo "Deuda, promesa y responsabilidad ¿es posible una desobediencia al neoliberalismo? Anacronismo e interrupción" (2020b). 


\section{La inquietud por el gobierno de la individualización}

La curiosidad de Foucault por los textos de Séneca, de Epicteto o de Marco Aurelio, se dirige a la recuperación de una experiencia histórica de sí mismo que no queda reducida a la constitución del sujeto de derecho. De modo que la cuestión es cómo el sujeto se constituye históricamente mediante artes de la existencia o técnicas de sí. Las relaciones entre sujeto y verdad en la antigüedad grecorromana no se enlazan, como a partir del cristianismo, desde el exterior y en una posición de poder dominante, sino a partir de una elección irreductible de existencia. Es elocuente en este sentido lo expresado a Hubert Dreyfus y Paul Rabinow en una entrevista de 1983, en la que sostiene que el problema para los griegos no era si Dios existía o qué pasa después de la muerte, sino ¿cuál es la tekhne que debo usar para vivir tan bien como debería vivir? La ética griega estaba centrada en un problema de elección personal, en una estética de la existencia: "La idea del bios como un material para una obra de arte es algo que me fascina. También la idea de que la ética puede ser una estructura muy vigorosa de la existencia, sin ninguna relación con lo jurídico per se, con un sistema autoritario, con una estructura disciplinaria (...)" (Dreyfus y Rabinow, 2001, p. 268).

Foucault había trabajado en el registro técnico-político a partir del cual se constituyen los cuerpos dóciles, y había expresado las diferencias entre el poder de soberanía y el poder disciplinario. También había desarrollado, como mencionamos antes, la dimensión biopolítica de esa nueva mecánica del poder que surge entre los siglos XVII y XVIII. Mediante estos desplazamientos podemos percibir también su interés por problematizar en torno a modos de resistencias subjetivos aquellas instancias de dominación. En este contexto, no debiéramos perder de vista que sigue guiándolo la misma inquietud en torno a las luchas contra un gobierno de la individualización; luchas contra el poder que nos convierte en individuos. En "El sujeto y el poder", el filósofo francés expresa que en las luchas actuales no se trata solamente de luchas antiautoritarias (del varón sobre la mujer, de los padres sobre los hijos, de los médicos sobre los enfermos), sino más bien de “(...) luchas contra el gobierno de la individualización (...)” (Foucault, 2001b, p. 244), que cuestionan el status del individuo, su derecho a ser diferente.

El gobierno de la individualización se habría formado a lo largo de siglos de cristianismo, y habría encontrado su morada en las instituciones. Su poder actúa separando el individuo, rompiendo sus vínculos con los demás, y 
atándolo a una identidad constrictiva; se aplica a la inmediata vida cotidiana “(...) que categoriza al individuo, le asigna su propia individualidad, lo ata en su propia identidad, le impone una ley de verdad sobre sí que está obligado a reconocer y que otros deben reconocer en él. Es una forma de poder que hace sujetos individuales (...)” (p. 245).

Es por esta razón que para Foucault el problema político, ético, social y filosófico de nuestros días es el de “(...) promover nuevas formas de subjetividad a través de esta especie de individualidad que nos ha sido impuesta por varios siglos (...)" (p. 249). Un diagnóstico similar es expresado en el marco de sus últimos cursos. En Subjetividad y verdad, lo hace al decir que la cultura cristiana habría tapado todo un paganismo, al que deberíamos tender: "(...) y si queremos volver al fondo de nosotros mismos, debemos sin dudas recuperar ese paganismo (...)" (2020, p. 55). En La hermenéutica del sujeto, Foucault sostuvo que nos encontramos ante la imposibilidad y, a la vez, ante la tarea urgente, fundamental y políticamente indispensable de constituir una ética de sí: “(...) si es cierto, después de todo, que no hay otro punto, primero y último, de resistencia al poder político que en la relación de sí consigo (...)" (2001a, p. 246).

Esta última expresión se encuentra en la trama argumentativa de la ampliación de la noción de 'gubernamentalidad', concebida como campo estratégico de las relaciones de poder, en el que hay que incluir a la relación de sí consigo -asunto por lo cual esta noción, además de la de 'bíos' puede considerarse un gozne en los desplazamientos teóricos, históricos y metodológicos. Esta ampliación permite retirar el tema de la gubernamentalidad del campo exclusivamente jurídico de la constitución del sujeto de derecho, algo de lo que el mismo Foucault se había ocupado también en la definición de la fábrica de cuerpos dóciles por oposición al modelo de la teoría política clásica, que parte de la abstracción del individuo. Esto es posible encontrarlo en numerosos pasajes de Vigilar y castigar -que acaso pueda ser leído como la continuación del trabajo genealógico de Nietzsche, en lo referido al estudio de la individualización de la pena y la constitución del individuo desde un registro técnico político ${ }^{6}$.

\footnotetext{
${ }^{6}$ Me refiero por ejemplo a pasajes como este: “(...) no hay que olvidar que ha existido en la misma época una técnica para constituir efectivamente a los individuos como elementos correlativos de un poder y de un saber. El individuo es sin duda el átomo ficticio de una representación «ideológica» de la sociedad; pero es también una realidad fabricada por esa tecnología específica llamada «disciplina» (...)” (Foucault, 2008b, p. 225).
} 
De esta manera la ampliación de la noción de gubernamentalidad, que como el mismo Foucault sostiene no pasa solo teórica, sino prácticamente por la relación de sí consigo, redefine la cuestión de la ética y la política en una única dimensión que la tradición jurídico-política hubiera separado, y destraba interpretaciones deterministas respecto de la productividad del poder-como si esa fábrica de individuos que constituyen las disciplinas no dieran lugar a formas de resistencias-, mostrando, en última instancia, las posibilidades de una microfísica del poder y la movilidad de las relaciones de fuerza.

Retomando la inquietud del pensador francés por las formas en que se produce la individualidad e identidad del sujeto, advertimos que es una preocupación transversal a lo largo del desarrollo de su pensamiento. La encontramos en La arqueología del saber, cuando manifiesta que la historia continua es el correlato de la función fundadora del sujeto. En aquel momento denunciaba una historia del pensamiento que se ampara bajo el techo del humanismo historia que en lo que sigue situaremos a partir de la respuesta platónica por el alma-sujeto, y que bien podemos ligar a esa tradición jurídico-política del sujeto de derecho-, que pretende ser la de las continuidades ininterrumpidas y que sirve de abrigo para la soberanía de la conciencia: "Hacer del análisis histórico el discurso del contenido y hacer de la conciencia humana el sujeto originario de todo devenir y toda práctica son las dos caras de un sistema de pensamiento (...)" (Foucault, 2004, pp. 20-21). Por el contrario, el tipo de diagnóstico de una arqueología nos desune de nuestras continuidades: disipa esa identidad temporal en que nos gusta contemplarnos a nosotros mismos para conjurar las rupturas en la historia: "Establece que somos diferencia, que nuestra razón es la diferencia de los discursos, nuestra historia la diferencia de los tiempos, nuestro yo la diferencia de las máscaras (...)” (p. 223). De modo que la labor de diagnóstico posibilita no la comprobación de nuestra identidad, sino la dispersión de lo que somos; aspecto que podemos encontrar cada vez que Foucault hace referencia a su trabajo filosófico como trabajo crítico del pensamiento.

Hacemos una última mención a esta insistencia sobre el trabajo filosófico en contra del gobierno de la individualización. En su reflexión sobre el método genealógico en Nietzsche, la genealogía, la historia, Foucault sostiene que la historia será efectiva en la medida en que “(...) divida nuestros sentimientos; dramatice nuestros instintos, multiplique nuestro cuerpo y lo oponga a sí mismo" (2008a, p. 47). Es decir, la historia será efectiva en cuanto se asuma 
otra concepción respecto de lo que nos define, y no simplemente la de la individualidad e identidad del yo: "Porque esta identidad, bien débil, no obstante, que tratamos de reunir y preservar bajo una máscara, no es más que una parodia: lo plural la habita, innumerables almas se enfrentan a ella; los sistemas se entrecruzan y se dominan unos a otros (...)" (p. 66).

Queremos retener estas últimas palabras para mostrar que el desarrollo teórico en torno al bíos y a una ética de sí, se encuentra lejos de propiciar el individualismo. Por el contrario, Foucault había emprendido el rescate de una historia marginal y olvidada, donde efectivamente los sistemas -el modelo de la reminiscencia platónico, el modelo del ascetismo pagano de la cultura de sí en los estoicos, y el modelo del ascetismo cristiano- se entrecruzaban. Sostenemos, entonces, que es necesario situar teóricamente las técnicas de sí, en general, y la cuestión del bíos, en particular, en el marco de una política de la desindividualización que colabora con la caída de la máscara de la identidad, para mostrar finalmente que la pluralidad nos habita.

Ofrecemos un ejemplo respecto a las discontinuidades y a la pluralidad del bíos antiguo, antes de exponer las dos historias a las que da lugar la tradición filosófica de la inquietud de sí. En la lección del 24 de febrero de 1982, Foucault analiza a partir de Marco Aurelio una práctica que define cierto movimiento del sujeto de hundimiento en el mundo, para examinarlo en sus más pequeños detalles. Ese ejercicio es una prueba de la discontinuidad de las cosas del mundo - discontinuidad que aparece como preocupación, como lo mencionamos, en su trabajo arqueológico y genealógico. La técnica posibilita ver las cosas, no en su gran unidad, sino en su dispersión. A propósito de ello, aplicándolo a nuestra propia existencia, Marco Aurelio decía que nuestro pneuma no es otra cosa que un soplo que se renueva con cada respiración, y por lo tanto "nunca somos los mismos" (Foucault, 2001a, p. 293). Foucault sostiene al respecto:

Por lo tanto, debemos aplicar a nosotros mismos, a nuestra propia vida, el ejercicio de la discontinuidad que hay que practicar con las cosas. Y al aplicarlo a nosotros mismos, advertiremos que ni siquiera lo que creemos nuestra identidad, o aquello en que suponemos necesario ubicarla o buscarla, garantiza nuestra continuidad. Siempre somos, al menos como cuerpo e incluso como pneuma, algo discontinuo con respecto a nuestro ser. Nuestra identidad no está allí (p. 294). 
El pasaje que analiza Foucault pertenece a las Meditaciones de Marco Aurelio (1977), y contrasta con las famosas Meditaciones metafísicas de René Descartes, quien ante la pregunta ¿qué soy? responde: "Lo he dicho: una cosa que piensa. ¿Y qué más? No soy este montón de miembros al que se llama cuerpo humano; no soy un aire fino y penetrante expandido por todos esos miembros; no soy un viento, un soplo, un vapor, ni nada de todo eso que puedo fingir o imaginar (...)" (2014, p. 21). La respuesta cartesiana no solo reconduce hacia el dualismo de cuerpo y alma, sino a una metafísica de la identidad y a una ontología del yo. Frente a aquella misma pregunta, Marco Aurelio, quince siglos antes, decía: “(...) esto es todo lo que soy: un poco de carne, un breve hálito vital (...)”, y por tanto nunca podremos encontrar allí la identidad, sino la diferencia, el cambio, la discontinuidad, dado que se trata de un "(...) viento, y no siempre el mismo, pues en todo momento se vomita y de nuevo se succiona (...)” (1977, pp. 59-60). De este modo, podemos tomar nota de dos tradiciones y genealogías posibles del gnothi seauton, o conócete a ti mismo, que no se reducen a periodos históricos, sino al juego de visibilidades e invisibilidades de cada una de estas tradiciones. Dos Meditaciones, dos respuestas, una antigua y la otra moderna. Ello anticipa el próximo apartado, en el que daremos cuenta de esas dos tradiciones a partir de dos respuestas a qué es 'el sí mismo' de la inquietud de sí.

\section{Dos historias contrapuestas en el desarrollo de la inquietud de sí}

En el apartado anterior señalamos que, ante las luchas contra el gobierno de la individualización, es urgente y políticamente indispensable la constitución de una ética de sí, aunque esa tarea resulte aparentemente imposible. El mismo Foucault sostuvo en varias oportunidades que las técnicas de sí de la Antigüedad no son soluciones extrapolables a nuestros problemas actuales. Por un lado, porque no se trata de una búsqueda de las soluciones, sino de las genealogías de los problemas. Por otro, por su interés teórico en la constitución de la subjetividad en el periodo helenístico y romano de los siglos I y II de nuestra era, mediante una relación de sí consigo que no se encuentra mediada por un sistema social, legal o institucional, sino que constituye una ética que es una estética de la existencia (Foucault, 2001b, pp. 263-264).

Sin embargo, no tenemos que ignorar o desconocer que todo el trabajo volcado sobre sus cursos, desde 1980 en adelante, es para mostrar dos tradiciones respecto de la introducción del tema de la inquietud de sí en la reflexión 
filosófica. En todo caso, si bien no se trata de replicar soluciones antiguas a problemas nuevos, sí de quitar el polvo que ha recubierto otras formas de relación consigo mismo, que no pasan por el código de la moral cristiana ni por las instancias jurídicas de las instituciones. Esto vale también para lectores desprevenidos -que no han profundizado en los desarrollos teóricos e históricos que conforman ese conjunto de prácticas y ejercicios sobre sí mismos-, que hacen uso de los conceptos de Foucault relativos a la cultura de sí, para adjudicarlos a las técnicas de coaching ontológico en el marco del empresario de sí mismo en la actual gubernamentalidad neoliberal. De más está decir que las técnicas aplicadas al neosujeto redundan en lo que hemos definido como "gobierno de la individualización", por una sencilla razón: son técnicas ancladas en el sistema de obligación-recompensa de una servidumbre de sí. Mientras que las técnicas de sí, en el estoicismo, se dirigían a romper el círculo obligación-endeudamiento de sí y con respecto a sí (2001a, p. 265). De modo que si se trata o no de "las mismas" técnicas, es una discusión que no tiene lugar, en la medida en que no se atiende a las diferencias específicas de una y otra experiencia histórica, en lo relativo a la configuración subjetiva como efecto de un código que funciona en el marco de una servidumbre de sí, y otra mediante una práctica de libertad.

Cuando hablábamos del enfoque de Foucault respecto de las relaciones entre sujeto y verdad, anticipamos que en La hermenéutica del sujeto se abordan las mencionadas relaciones a partir de la noción de epimeleia heautou o inquietud de sí; noción olvidada y oscurecida por otro precepto que primó y organizó la historia del pensamiento occidental: el gnothi seauton o conócete a ti mismo. No es nuestra intención aquí reconstruir el curso, sino destacar la pregunta a partir de la cual podemos desempolvar una historia que ha sido olvidada en torno a la formación de nuestra propia subjetividad y, además, presentar la inquietud de sí no solamente como aquel conjunto de prácticas y ejercicios espirituales de relación consigo mismo en la Cultura de Oro, sino como una forma de relación con nosotros mismos, que ha tenido diferentes momentos a lo largo de la historia, que ha sido retomada en distintos momentos, y sobre lo que tenemos la posibilidad de realizar esa tarea políticamente urgente ante el gobierno de la individualización. Hay varios ejemplos del rastrillaje realizado por Foucault de aquella historia olvidada en las relaciones entre sujeto y verdad, aunque sin una elaboración acabada, probablemente debido a su muerte. Encontramos un ejemplo en el pasaje referido a la constitución 
de una ética de sí como tarea urgente en nuestro tiempo, cuando el filósofo francés se encuentra analizando la prescripción del retorno estoico a sí, diferenciándolo de lo que se constituirá en el ascetismo cristiano como un rechazo de sí. El filósofo francés revela en este pasaje el esfuerzo de alcanzar una ética de sí como un tema recurrente en la cultura moderna -entre quienes se menciona a Montaigne y al pensamiento del siglo XIX: Schopenhauer, Nietzsche, Baudelaire, al anarquismo, como una serie de intentos de constituir una ética de sí (pp. 245-246). En este sentido: no se trata de soñar con la tarea imposible de constituir una nueva subjetividad, librada de los corsés individuales, sino de comprender que también aquella otra subjetivación hace nuestra historia, que en todo caso es lo que se encuentra tan lejos y tan cerca de nosotros ${ }^{7}$.

En la lección del 13 de enero de 1982, a propósito del análisis de la inquietud de sí en el momento socrático-platónico, en general, y de la lectura del Alcibíades de Platón, en particular, Foucault plantea las preguntas: ¿qué es ocuparse de sí mismo? ¿Qué es ese sí mismo del que hay que ocuparse? "¿Qué es ese elemento idéntico que, en cierto modo, está presente de uno a otro extremo de la inquietud de sí: sujeto de la inquietud, objeto de la inquietud?" (p. 67).

Hay dos historias producto del momento platónico de la inquietud de sí y del decir veraz, que responden a qué es ese 'sí mismo' del cuidado de sí. Una de éstas gozó de mayor difusión y privilegio, y responde con el alma-sujeto, conclusión a la que llega Foucault a partir de la lectura de Alcibíades. La otra historia quedó velada, y es la que responde con el bios, a la que también llega Foucault mediante el análisis del Laques, que tuvo recepción y desarrollo en la filosofía estoica, epicúrea y cínica de los primeros siglos de nuestra era. En uno y otro texto platónico se presenta el tema de la formación de un joven y la relación entre educación y negligencia, por lo cual es necesario el principio del cuidado de sí. Pero a diferencia del Alcibíades, de lo que hay que ocuparse en Laques no es del alma, sino del bios, de la manera de vivir:

Cuando comparamos el Laques y el Alcibíades, nos encontramos ante el punto de partida de dos grandes líneas de evolución de la reflexión y la práctica de la filosofía: la filosofía como aquello que, al inclinar, al incitar a los hombres

\footnotetext{
${ }^{7}$ He publicado recientemente un artículo sobre el trabajo metodológico con un tipo de a priori histórico que denomino metafóricamente 'faraway, so close' (2021), para determinar cómo la "prehistoria" (Nietzsche) y "lo originario" nos son contemporáneos.
} 
a ocuparse de sí mismos, los lleva hacia una realidad metafísica que es la del alma, y la filosofía como una prueba de vida, una prueba de la existencia y la elaboración de cierta forma y modalidad de vida (...) (2010, p. 141).

Y continúa:

(...) tenemos allí el punto de partida de dos aspectos, dos perfiles en cierto modo, de la actividad filosófica, de la práctica filosófica en Occidente. Por un lado, una filosofía que tiene que situarse bajo el signo del conocimiento del alma, y que hace de este conocimiento del alma una ontología del yo. Y además, una filosofía como prueba de vida, del bios que es materia ética y objeto de un arte de sí mismo (...) (p. 141).

En la primera tradición, la respuesta por el sí mismo del que hay que ocuparse es el alma, con lo que otorga importancia a la contemplación de ésta y a reconocer en ella el elemento divino. A partir de esta respuesta se despliega, a lo largo de toda la Edad Media, y por motivo de la teología, el primado del gnothi seauton por sobre la inquietud de sí. Es decir, la gran historia del autoconocimiento que supone tener que decir una verdad sobre sí mismo, esa obligación o constricción moral, institucionalizada en el plano jurídico también, de decir la verdad.

En la primera clase de La hermenéutica del sujeto, pasando revista rápidamente por esta primera historia, Foucault señala cómo en la Modernidad cambian las relaciones entre sujeto y verdad en el momento cartesiano; momento en el que el sujeto ya no necesita transformarse para acceder a la verdad, pues ésta se sitúa en la evidencia del cogito y se reduce a un mero acto de conocimiento (2001a, pp. 32-37). Confluyen, en este desarrollo, tanto el modelo platónico de la reminiscencia como el modelo de la exégesis del cristianismo.

Sostenemos entonces que ambos modelos -el socrático-platónico y el del ascetismo cristiano- se inscriben además en aquello que Foucault, algunos años antes, denominó “el gran libro del Hombre-máquina”:

El gran libro del Hombre-máquina ha sido escrito simultáneamente sobre dos registros: el anátomo-metafísico, del que Descartes había compuesto las primeras páginas y que los médicos y filósofos continuaron, y el técnicopolítico, que estuvo constituido por todo el conjunto de reglamentos militares, escolares, hospitalarios, y por procedimientos empíricos y reflexivos para controlar o corregir las operaciones del cuerpo (...) (2008b, p. 158). 
Este pasaje de Vigilar y castigar expresa que la constitución de cuerpos dóciles para el despegue económico del capital se basa en ambas operaciones: la de la normalización y disciplinamiento de los cuerpos, y la de una ontología del yo. Pero esa metafísica del alma ha sentado además las bases para la instauración del individuo como titular de derechos, razón por la cual Foucault expresa que "(...) las disciplinas reales y corporales han constituido el subsuelo de las libertades formales y jurídicas (...)” (p. 255). De esta manera, "La individualización aparece como el objetivo último de un código adaptado en forma exacta (...)” (p. 114). Tenemos aquí, entonces, una primera historia para la que el sí mismo es el alma.

La otra historia, más difícil de realizar en cuanto ha quedado reabsorbida por el primado del 'conócete a ti mismo', ante la cuestión acerca de qué es el sí mismo, sujeto y objeto de la inquietud de sí, responde que es el bíos, la forma de vida como objeto de una elaboración. ¿Qué quiere decir que sea objeto de una elaboración? Foucault presenta la epistrophe o conversión de sí entre epicúreos y estoicos, para explicar el desplazamiento que el sujeto debe realizar para una autosubjetivación o, dicho más claramente, para alcanzar un sí mismo que no se da de modo previo. Se trata de un trabajo ethopoiético, en cuanto intervención de sí mismo sobre la propia configuración subjetiva ${ }^{8}$. A diferencia de la tradición del autoconocimiento - que constituyó uno de los registros para la docilidad del cuerpo y la separación de la ética y la política-, no se presenta una experiencia metafísica del mundo, sino una experiencia histórico-crítica de la vida (Foucault, 2010, p. 326).

¿Qué es ese bíos, que puede formarse y transformarse? La noción aparece en Subjetividad y verdad. Foucault sostiene allí que los griegos tenían dos verbos para designar aquello para lo que nosotros poseemos una sola palabra: 'vivir'. Por un lado 'zen', que quiere decir que algo tiene la propiedad de vivir, es decir, que se trata de una condición del ser vivo:

Y está la palabra bioun, que quiere decir: pasar la vida, y que se relaciona con la manera de vivir esta vida, la manera de llevarla adelante, de conducirla, el modo en que puede calificársela de dichosa o desdichada. El bíos es algo que puede ser bueno o malo, en tanto que la vida que uno lleva porque es un ser vivo le ha sido simplemente dada por naturaleza. El bios es la vida

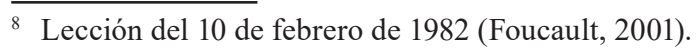


calificable, la vida con sus accidentes y sus necesidades, pero es también la vida tal como uno mismo puede hacerla, decidirla. El bios es lo que nos pasa, por supuesto, pero desde la óptica de lo que hacemos con lo que nos pasa. Es el curso de la existencia, pero habida cuenta del hecho de que ese curso está ineludiblemente ligado a la posibilidad de llevarlo adelante, transformarlo, dirigirlo en este o aquel sentido, etc. El bios es el correlato de la posibilidad de modificar la propia vida, modificarla de una manera racional y en función de los principios del arte de vivir (...) (2020, p. 50)9.

La respuesta es la del modelo del ascetismo pagano, que incluye a la tradición del cinismo que Foucault no solo aborda como una figura particular de la filosofía antigua, sino a la que se refiere también como una actitud recurrente a lo largo de toda la filosofía occidental -aspecto este último que manifiesta su voluntad por mostrar que acaso haya habido en la historia varios esfuerzos para construir esa ética de sí. En El coraje de la verdad Foucault opone estas dos historias, mostrando que aquella que responde al momento socrático platónico y cristiano planteó en el fondo la cuestión del otro mundo, del más allá, mientras que el cinismo instala el problema de la vida otra, que no significa simplemente "cambiar de modo de vida", como podríamos entenderlo hoy, sobre aspectos de la cotidianidad, sino del desarrollo de un arte de vivir y una manera de vivir: “(...) solo puede haber verdadera vida como vida otra (...)” (2010, p. 325), y el escándalo cínico consiste en esa alteridad misma de la vida mostrándose como otra ${ }^{10}$.

Ahora bien, como dijimos, no se trata de dar una solución antigua a nuestros problemas actuales, ni de universalizar una ética de sí. La cuestión, a la vez histórica y metodológica que Foucault quiere plantear, como él mismo lo refiere, es no dejarse atrapar por el proceso de juridización:

\footnotetext{
9 El pasaje resulta familiar para quienes leyeron en primera instancia el Homo sacer de Giorgio Agamben, quien hiciera célebre la distinción entre bíos y zoé a partir de sus lecturas de Foucault y antes de publicarse este curso (Agamben, 2017, p. 11).

${ }^{10}$ Foucault presenta la originalidad de su investigación en contraste con Pierre Hadot, al mostrar que éste había analizado dos grandes modelos respecto de la conversión de sí en la cultura occidental: la epistrophe platónica y la metanoia cristiana. Su trabajo busca una grilla de análisis que permita explicar qué pasó en el periodo que se extiende desde Platón hasta el cristianismo, e introduce, de esta manera, el modelo de la conversión en el estoicismo, epicureísmo y cinismo de la Antigüedad grecorromana (Foucault, 2001a, pp. 216-217), lo que coincide con esta segunda historia respecto del bíos como sí mismo del que hay que ocuparse. Mientras los modelos estudiados por Hadot son los que recubrieron el modelo helenístico (249).
}

Vignale, S. (2021). La vida en sentido extramoral. Ensayo sobre la inquietud de sí como 
¿Podemos decir que la inquietud de sí constituye ahora una especie de ley ética universal? Ustedes me conocen lo suficiente para suponer que voy a responder de inmediato: no. Lo que me gustaría mostrar, la apuesta metodológica de todo esto (una parte, en todo caso), es que: no hay que dejarse atrapar por ese proceso histórico ulterior que se desarrolló en la Edad Media, y que fue la juridización progresiva de la cultura occidental. Juridización que nos hizo tomar la ley como el principio general de toda regla en el orden de la práctica humana. Lo que querría mostrarles, al contrario, es que la ley misma forma parte, como episodio y forma transitoria, de una historia mucho más general, que es la de las técnicas y tecnologías de las prácticas del sujeto en referencia a sí mismo, técnicas y tecnologías que son independientes de la forma de la ley, prioritarias con respecto a ellas (...) (2001a, pp. 118-119).

La ley, en todo caso, no es más que uno de los aspectos de esta larga historia durante la cual se constituyó el sujeto occidental. Por tanto, nos encontramos en mejores condiciones de entender en qué medida la inquietud de sí constituye una política de la desindividualización. Si de un lado encontramos una historia -la historia del autoconocimiento que mediante un largo proceso de juridización termina en el sujeto de derecho y en la identidad metafísica del yo-, del otro, hay una historia mediante la cual es posible encontrarse con otros aspectos que no se encuentran gobernados por el poder de la individualización.

Si atendemos al doble registro en que se ha escrito el gran libro del Hombremáquina, es relevante considerar también cómo se gestionan las fuerzas tanto en una historia como en otra. En relación con la producción de la individualidad, hemos estudiado en Vigilar y castigar una determinada gestión de las fuerzas por parte del anátomo-poder. En este escrito se afirma, a propósito de la constitución de los cuerpos dóciles, que la disciplina, como arte de la composición y descomposición de las fuerzas, “(...) aumenta las fuerzas del cuerpo (en términos de utilidad económica) y disminuye esas mismas fuerzas (en términos de obediencia política). En una palabra: disocia el poder del cuerpo (...)" (2008b, p. 160). Podríamos decir, en otras palabras, que se trata de una operación de separar a la fuerza de aquello que puede, o de lo que puede analizarse como un devenir reactivo de las fuerzas en el marco de una genealogía de la moral.

Ahora bien, ofrecemos un ejemplo de gestión de las fuerzas a favor de la vida. En la edición reciente de Historia de la sexualidad 4, Las confesiones de la carne, hay un fragmento en el que se analizan las formas episódicas 
de dirección de la vida y el examen de uno mismo, que nos permite pensar en resistencias subjetivas a partir de la relación de sí consigo mediante el balance de las fuerzas del cuerpo. Se trata de un análisis de Foucault acerca de un texto de Séneca, en el que Sereno solicita ayuda para dar con el nombre de la enfermedad que lo aqueja:

Al adentrarse paso a paso en la filosofía estoica, Sereno pide la ayuda del filósofo en un momento en que siente algo semejante a un malestar: la sensación de haber dejado de avanzar, el temor de que el apego a lo que está mal y a lo que está bien no se haya instalado de manera definitiva, el sentimiento de estar inmovilizado en un estado que no termina de ser la liberación ni la esclavitud. En síntesis, Sereno no está ni enfermo ni sano. El examen a que se entrega entonces para que Séneca pueda intervenir, diagnosticar y proponer remedios consiste en trazar una suerte de balance de las fuerzas: ¿cuáles son las que aseguran la estabilidad del alma, su calma, su independencia? ¿Y cuáles las que, al contrario, la exponen a la perturbación exterior y la ponen bajo la dependencia de lo que no le pertenece? (Foucault, 2019, p. 131).

Si bien el fragmento está destinado a mostrar que el examen de Séneca no busca las causas de la enfermedad, sino la evaluación de un estado, las preguntas expuestas por Foucault dan cuenta de las fuerzas en sentido extramoral: no se trata de determinar qué es lo bueno o lo malo; se trata de determinar el balance de las fuerzas en el estado actual de Sereno. Frente a aquella gestión de nuestras fuerzas que busca aumentarlas en términos de utilidad económica y disminuirlas para volvernos obedientes, el fragmento llama la atención porque no se trata de una gestión de las fuerzas impuesta "desde afuera", sino de su balance en la relación consigo mismo, lo que nos pone frente a prácticas concretas de resistencias.

\section{Bíos e inquietud de sí como política de la desindividualización}

Nos preguntamos, entonces, en qué medida una historia de bíos se aproxima a una política de la desindividualización. Otra vez: no para fundar una nueva subjetividad, ni tampoco en ejercicio de un anacronismo para sostener que las antiguas técnicas de sí puedan simplemente ejercitarse en nuestra actualidad sin más. La pregunta se dirige a percibir en nosotros mismos las huellas de aquella otra historia.

La noción de 'bíos' presenta cierta dificultad para que comprendamos a qué se referían con ella los griegos. En principio, en cuanto supone un equivalente 
de lo que nosotros llamamos 'el sujeto', no es, sin embargo, coincidente con él. Por una parte, asociamos la vida a la profesión y a cierto status. Luego de siglos de cristianismo, nuestra manera de concebir la vida es definida en relación a otro mundo, oscilando entre esta vida y la vida en el más allá, que es la forma como el cristianismo reinterpretó la conversión estoica de sí; como rechazo o renuncia de sí, y no como un alcanzarse a sí mismo. En segundo lugar, esta noción es importante en la medida en que Foucault la opone al conducirse mediante un código de comportamiento, lo que expresaría las grandes diferencias en lo que respecta a la conducción moral y a la constitución subjetiva a partir del cristianismo. En el marco de su definición de los aphrodisia griegos, el filósofo francés expresa que aquellos “(...) no son códigos, ni exactamente sistemas prescriptivos, ni conjuntos teóricos. Se presentan como tekhnai (técnicas) perí ton bion (que tienen por objeto la vida)" (2020, p. 265).

Podemos observar su especial interés en este curso, y en los siguientes, por detenerse y definir esas tekhne que buscan "(...) efectuar pues en un objeto determinado transformaciones con vistas a ciertos fines (...)" (p. 265), que en el caso de las tekhne tou biou, tienen como objetivo la transformación de la propia vida. El bíos es "(...) la forma de relación que uno mismo decide tener con las cosas, la manera de situarse con respecto a ellas (...)”, y además “(...) la manera de inscribir su propia libertad, sus propios fines, su propio proyecto en las cosas mismas, la manera, en cierto modo, de ponerlas en perspectiva y utilizarlas (...)” (p. 267).

La diferencia entre el bios -la subjetividad griega, como Foucault le llama-, y nuestra forma de subjetividad, es que nosotros tenemos un gran modelo de subjetividad "constituido, primero, por una relación con un más allá; segundo, por una operación de conversión, y tercero, por la existencia de una autenticidad, una verdad profunda por descubrir y que constituiría el fondo, el basamento, el suelo de nuestra subjetividad. Sin duda es esto lo que el cristianismo construyó durante siglos" (p. 267).

En la reconstrucción genealógica que realizamos en torno a la historia de una ontología del yo y del disciplinamiento de los cuerpos - como formas acabadas de este gobierno de la individualización-, consideramos fundamental el trabajo de Nietzsche como antesala de los desarrollos realizados por Foucault. Con lo dicho hasta el momento hemos hecho converger, entonces, 
dos genealogías. Por un lado, la genealogía de Nietzsche en torno a cómo la vida se constituyó en un error -la hostilidad metafísica a la vida, su negación, el envenenamiento del ideal ascético- y una genealogía del Hombremáquina, coincidente con la historia del autoconocimiento en el pensamiento occidental. Ese gran modelo de nuestra subjetividad es el modelo del ideal ascético: que la voluntad humana necesite de un más allá que niega la vida, y a partir del que se valora todo acto de renuncia. Las marcas del ideal ascético se corresponden con una "actividad maquinal" que termina traduciéndose en "olvidarse-de-sí-mismo, para la incura sui [descuido de sí]” (Nietzsche, 1998, p. 156). Nietzsche describe de esta manera, entonces, el ejercicio de los sacerdotes del ideal ascético, afirmando que:

(...) esta vida (junto a todo lo que a ella pertenece, «naturaleza», «mundo», la esfera entera del devenir y la caducidad) es puesta por ellos en relación con una existencia completamente distinta, de la cual es antitética y excluyente, a menos que se vuelva en contra de sí misma, que se niegue a sí misma: en este caso, el caso de una vida ascética, la vida es considerada como un puente hacia aquella otra existencia (p. 136).

De modo que la vida regulada, que surge de la doble operación de escritura del libro del Hombre-máquina, no sería posible sin el código moral que la desprecia. Por el contrario, el bíos -entendido como lo hemos expuesto aquíen la medida en que no responde a códigos de comportamientos impuestos, se encuentra más allá del bien y del mal: en un sentido extramoral de la moralidad cristiana y de un sistema jurídico o disciplinario.

\section{A modo de síntesis}

Hemos presentado a lo largo de este escrito la convergencia de dos genealogías para describir una única historia, que es la de cómo hemos llegado a ser los sujetos que somos mediante la respuesta platónica del alma como sujeto de la inquietud de sí. El modelo platónico de la reminiscencia, junto al ascetismo cristiano, han constituido aquel registro anátomo-metafísico mencionado por Foucault como una de las escrituras del gran libro del Hombre-máquina. Escritura que, junto al registro técnico político, ha consolidado el poder de individualización. La vida que se desprende de esta forma de subjetividad es una vida regulada por los códigos de comportamiento, lo que en términos de la genealogía de Nietzsche hemos descrito mediante el desprecio a la vida por medio del ideal ascético. 
Por otra parte, hemos buscado rescatar la historia del modelo propio del ascetismo pagano, que responde de otra forma a la cuestión (sobre qué es el sí mismo) del cual hay que ocuparse. También se ha presentado el bíos como una forma de vida que no se encuentra ajustada a los códigos de comportamiento, sino a prácticas que tienen por objetivo alcanzar, constituir, un sí mismo.

Con atención a situar estas historias en el marco de la inquietud teórica de Foucault por una ética de sí y contra el gobierno de la individualización, sostuvimos que el estudio en torno a la epimeleia heautou se presenta en el marco de su trabajo crítico filosófico como una política de la desindividualización. Esto supone, además, que más allá o más acá de determinar si una ética de sí es posible en el presente, es relevante considerar -y esta ha sido nuestra apuesta- que la importancia de rescatar la historia del bios, oscurecida por la historia del autoconocimiento y del sujeto de derecho, nos pone frente a la posibilidad de rescatar también algo de nuestra propia historia occidental, referida a la configuración de nuestra subjetividad. El pulso lejano de aquella historia debe llegar a nosotros sutilmente, como llega la radiación del lejano origen del universo a nuestro planeta.

\section{Referencias}

Agamben, G. (2017). Homo sacer. El poder soberano y la vida desnuda (M. Ruvituso, Trad.). Buenos Aires: Adriana Hidalgo Editora.

Descartes, R. (2014). Meditaciones metafísicas; seguidas de las objeciones y respuestas (J. A. Díaz, Trad.). Barcelona: RBA / Gredos.

Dreyfus, H. y Rabinow, P. (2001). Michel Foucault; más allá del estructuralismo y la hermenéutica (R. Paredes, Trad.). Buenos Aires: Nueva Visión.

Foucault, M. (1999). La verdad y las formas jurídicas. Obras esenciales (F. Álvarez Uría y J. Varela, Trad.). Barcelona: Paidós.

Foucault, M. (2001a) La hermenéutica del sujeto. Curso en el Collège de France: 1982-1983 (H. Pons, Trad.). Buenos Aires: Fondo de Cultura Económica.

Foucault, M. (2001b). Post-scriptum. El sujeto y el poder (R. Paredes, Trad.). H. Dreyfus y P. Rabinow (Eds.), Michel Foucault; más allá del 
estructuralismo y la hermenéutica (pp. 241-259). Buenos Aires: Nueva Visión.

Foucault, M. (2004). La arqueología del saber (A. Garzón del Camino, Trad.). Buenos Aires: Siglo XXI.

Foucault, M. (2008a). Nietzsche, la genealogía, la historia (J. Vázquez Pérez, Trad.). Valencia: Pre-textos.

Foucault, M. (2008b). Vigilar y castigar: nacimiento de la prisión (A. Garzón del Camino, Trad.). Buenos Aires: Siglo XXI.

Foucault, M. (2009). Historia de la sexualidad 1: La voluntad de saber (U. Guiñazú, Trad.). Buenos Aires: Siglo XXI.

Foucault, M. (2010). El coraje de la verdad. Curso en el Collège de France: 1983-1984 (H. Pons, Trad.). Buenos Aires: Fondo de Cultura Económica.

Foucault, M. (2012). Lecciones sobre la voluntad de saber. Curso en el Collège de France: 1970-1971 (H. Pons, Trad.). Buenos Aires: Fondo de Cultura Económica.

Foucault, M. (2014). El gobierno de los vivos. Curso en el Collège de France: 1979-1980 (H. Pons, Trad.). Buenos Aires: Fondo de Cultura Económica.

Foucault, M. (2019). Historia de la sexualidad 4: Las confesiones de la carne (H. Pons, Trad.). Buenos Aires: Siglo XXI.

Foucault, M. (2020). Subjetividad y verdad. Curso en el Collège de France: 1980-1981 (H. Pons, Trad.). Buenos Aires: Fondo de Cultura Económica.

Marco Aurelio (1977). Meditaciones (R. Bach Pellicer, Trad.). Madrid: Gredos.

Nietzsche, F. (1998). La genealogía de la moral, un escrito polémico (A. Sánchez Pascual, Trad.). Madrid: Alianza.

Vignale, S. (2020a). Ethos crítico y a priori histórico de una experiencia posible. Contribución filosófica a la noción de crítica desde una ontología del presente. REDEA. Revista Derechos en Acción, 14 (14), pp. 858-882. https://doi.org/10.24215/25251678e380 
Vignale, S. (2020b). Deuda, promesa y responsabilidad ¿es posible una desobediencia al neoliberalismo? Anacronismo e interrupción. Revista de Filosofía política clásica y moderna, 10 (19), pp. 229-254. https:// publicaciones.sociales.uba.ar/index.php/anacronismo/article/view/4553

Vignale, S. (2021). Faraway, so close: a priori histórico para una arqueología filosófica de la pena. El Banquete de los Dioses. Revista de Filosofía y Teoría Política Contemporáneas, 8, pp. 58-84. https://publicaciones. sociales.uba.ar/index.php/ebdld/article/view/6524/5563 